\title{
Guide pratique à l'intention des laboratoires cliniques pour les tests de sérologie du SRAS-CoV-2
}

\author{
Carmen Charlton 1,2,3*, Jamil Kanji ${ }^{1,2,4}$, Vanessa Tran ${ }^{5,6}$, Julianne Kus ${ }^{5,6}$, Jonathan Gubbay ${ }^{5,6}$, \\ Carla Osiowy ${ }^{7}$, Jason Robinson ${ }^{8}$, Inna Sekirov ${ }^{9}$, Michael Drebot ${ }^{7}$, Todd Hatchette ${ }^{10}$, Derek Stein ${ }^{11,12}$, \\ Nadia El-Gabalawy ${ }^{7}$, Amanda Lang ${ }^{13}$, Lei Jiao ${ }^{10}$, Paul Levettt ${ }^{11}$, Heidi Wood ${ }^{7}$, Christian Therrien ${ }^{14}$, \\ L Robbin Lindsay ${ }^{7}$, Muhammad Morshed ${ }^{9}$, Jessica Forbes ${ }^{6}$, Antonia Dibernardo ${ }^{7}$ au nom du groupe \\ de travail sur la sérologie du Réseau des laboratoires de santé publique du Canada (RLSPC)
}

\section{Résumé}

Le répertoire des tests de diagnostic disponibles du coronavirus du syndrome respiratoire aigu sévère 2 (SRAS-CoV-2) évolue rapidement. Bien que les tests sérologiques aient une capacité de diagnostic limitée concernant l'infection aiguë, leur rôle dans les études épidémiologiques et dans la prise de décision en santé publique ainsi que pour l'émission de recommandations est de plus en plus important. Compte tenu de la disponibilité mondiale de vaccins, les laboratoires cliniques sont de plus en plus sollicités pour assurer le dépistage des anticorps et l'interprétation des résultats pour les personnes vaccinées et non vaccinées. Nous présentons ici les données les plus récentes sur les délais de production des anticorps contre le SRAS-CoV-2, notamment la longévité des anticorps, ainsi que la production et la détection des anticorps neutralisants. En outre, nous formulons des conseils pratiques destinés aux laboratoires de microbiologie clinique afin que ces derniers vérifient les tests sérologiques commerciaux et choisissent les algorithmes de test appropriés pour leurs populations locales.

Citation proposée : Charlton CL, Kanji JN, Tran V, Kus JV, Gubbay J, Osiowy C, Robinson JL, Sekirov I, Drebot M, Hatchette T, Stein DR, El-Gabalawy N, Lang A, Jiao L, Levett PN, Wood H, Therrien C, Lindsay LR, Morshed M, Forbes JD, Dibernardo A au nom du Groupe de travail sur la sérologie du Réseau canadien de laboratoires de santé publique (RLSPC). Guide pratique à l'intention des laboratoires cliniques aux fins des tests de sérologie du SRAS-CoV-2. Relevé des maladies transmissibles au Canada 2021;47(4):187-200.

https://doi.org/10.14745/ccdr.v47i04a01f

Mots-clés : COVID-19, SRAS-CoV-2, test sérologique, algorithmes de sérologie

\section{Introduction}

L'émergence du coronavirus 2 du syndrome respiratoire aigu sévère (SRAS-CoV-2) en décembre 2019 a entraîné un développement mondial rapide des tests moléculaires, antigéniques et sérologiques pour le diagnostic de l'infection aiguë et l'identification de l'infection passée. Alors que les tests moléculaires sont largement acceptés comme la méthode de référence concernant le diagnostic d'une infection aiguë, le rôle de la sérologie est limité à des cas cliniques particuliers en tant que complément au diagnostic (1). Les anticorps anti-SRAS-CoV-2 ne sont pas détectés de manière fiable moins de 7 à 21 jours après l'apparition des symptômes, ce qui limite leur utilité dans le diagnostic de l'infection aiguë (2-4). Cependant, dans des cas tels que le syndrome inflammatoire multiple chez l'adulte ou chez l'enfant, un résultat positif à un test sérologique peut aider à guider la prise en charge clinique en l'absence d'un résultat positif à un test moléculaire ou lorsque le test moléculaire n'est pas disponible, et des résultats sérologiques positifs ont été inclus dans la définition de cas clinique pour le syndrome inflammatoire multiple chez l'enfant (5). En dehors de ces scénarios cliniques très spécifiques, le rôle des tests sérologiques est de déterminer les taux de prévalence du SRAS-CoV-2 dans la population et de contribuer à éclairer les décisions de santé publique.
Cette oeuvre est mise à la disposition selon les termes de la licence internationale Creative Commons Attribution 4.0

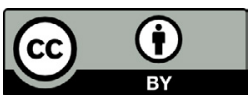

Affiliations

'Laboratoire de santé publique, Alberta Precision Laboratories, Edmonton, $A B$

2 Département de médecine de laboratoire et de pathologie, Université de l'Alberta, Edmonton, $A B$ ${ }^{3}$ Institut de virologie Li Ka Shing, Edmonton, $\mathrm{AB}$

${ }^{4}$ Division des maladies infectieuses, Département de médecine, Université de l'Alberta, Edmonton, AB

${ }^{5}$ Laboratoire de Santé publique Ontario, Toronto, ON

${ }^{6}$ Département de médecine de laboratoire et de pathobiologie, Université de Toronto, Toronto, ON

${ }^{7}$ Laboratoire national de

microbiologie, Agence de la santé publique du Canada, Winnipeg, MB

${ }^{8}$ Services de laboratoire provinciaux, Division de chimie clinique, Santé Î.-P.-É., Charlottetown, PE

9 Laboratoire de santé publique du British Columbia Centre for Disease Control, Vancouver, BC

${ }^{10}$ Laboratoire de microbiologie de santé publique de Terre-Neuve-etLabrador, St. John's, NL

1 Département de microbiologie médicale et de maladies infectieuses, Université du Manitoba, Winnipeg, MB

${ }^{12}$ Laboratoire provincial Cadham, Winnipeg, MB

${ }^{13}$ Laboratoire provincial Roy Romanow, Regina, SK

${ }^{14}$ Laboratoire de santé publique du Québec, Institut national de santé publique du Québec, Sainte-Anne-deBellevue, QC

${ }^{\star}$ Correspondance :

carmen.charlton@

albertaprecisionlabs.ca 
Pour améliorer l'utilité des tests sérologiques, il faut une norme internationale permettant une comparaison directe de la performance des tests entre les laboratoires cliniques. Des études à l'échelle de la population reliant les résultats sérologiques quantitatifs aux résultats cliniques seront nécessaires pour aider à déterminer quel niveau d'anticorps peut être corrélé avec l'immunité à l'infection. Ces approches seraient similaires à ce qui a été fait avec d'autres virus (e.g. la rubéole), où une norme internationale est utilisée pour étalonner les tests de détection quantitatif des immunoglobuline $\mathrm{G}(\mathrm{lgG})$ est utilisée pour déterminer l'immunité (plus de $10 \mathrm{UI} / \mathrm{ml}$ ) ou la susceptibilité (moins de $10 \mathrm{Ul} / \mathrm{ml}$ ) à l'infection, sur la base d'une corrélation avec les résultats cliniques $(6,7)$. De multiples essais sérologiques quantitatifs ont été soumis à des organismes d'agrément dans le monde entier, notamment la Food and Drug Administration (FDA), Santé Canada et le Conseil européen; toutefois, à ce jour, en Amérique du Nord, il y a un manque d'essais quantitatifs approuvés qui ont une corrélation avec l'immunité contre l'infection (i.e. les anticorps neutralisants). Bien que cela n'ait pas d'incidences sur la prise de décision clinique au niveau individuel, cela reste une lacune importante dans I'interprétation et l'utilité des tests sérologiques du SRAS-CoV-2 pour les études de sérosurveillance.

Nous examinons ici les connaissances actuelles sur les tests sérologiques, nous discutons des limites des tests, décrivons comment les laboratoires cliniques peuvent à la fois valider ces tests et mettre en œuvre des algorithmes appropriés pour les populations locales de patients, nous abordons le rôle de la différenciation des anticorps dérivés de l'infection naturelle par rapport à ceux qui sont dérivés du vaccin et nous examinons les options pour la détection des anticorps neutralisants.

\section{Délais de séroconversion}

La cinétique de production des anticorps au SRAS-CoV-2 est relativement bien étudiée; cependant, il existe une variabilité importante dans les délais de séroconversion étant donné I'hétérogénéité entre les populations étudiées (i.e. la gravité de la maladie, l'âge, la présence de comorbidités, etc.), les tests sérologiques utilisés et les marqueurs sérologiques analysés. En général, on estime que l'intervalle global de séroconversion, quel que soit le type d'anticorps, se situe entre quatre et 14 jours après l'apparition des symptômes $(2,8,9)$. Une première étude a évalué les taux de séroconversion chez 173 patients et a rapporté des délais médians de séroconversion pour les anticorps totaux (Ab), les immunoglobulines $M(\lg M)$ et les lgG qui étaient respectivement de 11, 12 et 14 jours. Cependant, les auteurs ont rapporté que moins de $40 \%$ des patients avaient des anticorps détectables dans la semaine suivant le début des symptômes et que ce chiffre passait à 100 \% (Ac total), 94 \% (lgM) et 80 \% (lgG) au 15e jour chez les mêmes patients (10). En revanche, une autre étude a indiqué que le taux de séroconversion de l'immunoglobuline $A(\lg A)$ était similaire à celui de l'IgM, avec une séroconversion médiane de cinq jours (Écart Interquartile 3-6) après l'apparition des symptômes, comparativement à 14 jours pour l'IgG (11). Malgré la détection plus précoce des IgM dans ces études, l'évolution des taux de séroconversion lgM et lgG est similaire pour le SRAS-CoV-2 par rapport à d'autres maladies infectieuses, où les IgM précèdent les IgG de quelques jours ou semaines. En effet, on a constaté que les signaux de détection des lgG et des lgM atteignaient un plateau six jours après le premier test sérologique positif chez 285 patients atteints de la maladie à coronavirus 2019 (COVID-19) (9). Ainsi, bien que les études s'accordent à dire que la séroconversion se produit dans les 4 à 14 jours suivant l'apparition des symptômes et que les dynamiques de séroconversion des lgG et des lgM sont similaires, la variabilité considérable entraîne une faible sensibilité des tests $d$ 'anticorps pour le diagnostic de la COVID-19 aiguë, ce qui a été bien documenté dans la littérature $(1,2,12)$.

\section{Longévité des anticorps}

La durée pendant laquelle les réponses immunitaires persistent, et confèrent éventuellement une protection contre la réinfection, est essentielle pour comprendre la dynamique de l'infection par le SRAS-CoV-2 (une chronologie détaillée de la détection des anticorps est présentée au point (9)). En utilisant des échantillons sériques séquentiels provenant de 65 patients et de 31 travailleurs de la santé séropositifs, Seow et al. (13) ont montré que la séroconversion des $\lg \mathrm{M}, \lg \mathrm{g}$ et $\lg \mathrm{A}$ se produisait dans plus de $95 \%$ des cas lorsque le prélèvement était égal ou supérieur à huit jours après l'apparition des symptômes. La cinétique des anticorps neutralisants était conforme à celle d'autres infections virales aiguës (13), avec un pic initial à 3-4 semaines (l'ampleur du pic dépend de la gravité de la maladie) suivi d'une diminution de la concentration des anticorps neutralisants. II est intéressant de noter que les patients dont la virémie est élevé présentent des Ac neutralisants plus longtemps que ceux dont le pic d'infectivité est faible (13). Le déclin du niveau des des anticorps neutralisants s'est produit en même temps que le déclin des lgG contre la glycoprotéine Spicule(S) du SRAS-CoV-2 et le domaine de liaison au récepteur (DLR), ainsi que celui des $\lg M$ et $\lg A$ contre la glycoprotéine $S$ et le DLR. Chez les patients atteints d'une maladie légère à modérée, on a constaté que les niveaux d'anticorps lgG étaient stables jusqu'à cinq mois, avec une corrélation significative entre les anticorps dirigés contre la spiculeet les anticorps neutralisants (14).

D'autres études qui utilisent des tests de séroneutralisation par réduction de plaque ou de microneutralisation en combinaison avec des essais immuno-enzymatiques (test ELISA) anti-spicule ont validé davantage les résultats de la durée longitudinale des anticorps neutralisants $(15,16)$. Les baisses des niveaux d'anticorps observées précédemment au cours des premiers mois suivant l'infection sont attendues, car les plasmocytes à courte durée de vie disparaisent; cependant, lorsque ceux-ci sont remplacés par des lymphocytes $B$ mémoires sécrétant des anticorps à longue durée de vie, les anticorps neutralisants persistent pendant plusieurs mois chez la plupart des individus (17). 
Il est intéressant de noter que des études sur la longévité des anticorps dans le sérum et la salive ont montré que les taux $d^{\prime} \lg M$ et d'lgA diminuaient rapidement après avoir atteint leur niveau maximal (18), tandis que les lgG restaient relativement stables dans les deux biofluides (jusqu'à 105 jours après I'apparition des symptômes). De même, d'autres ont constaté la présence d'anticorps lgG 3 à 6 mois après l'apparition des symptômes chez $92,3 \%$ des patients $(N=427)$ (19). Bien que la plupart des données suggèrent que les taux d'anticorps $\lg \mathrm{M}$ et $\lg \mathrm{A}$ diminuent de manière significative par rapport aux isotypes lgG, chez les patients convalescents de la COVID-19, ils semblent jouer un rôle clé dans la réponse humorale initiale de neutralisation. Il a été démontré que les lgA sériques contribuent à la neutralisation du virus jusqu'à un mois après l'apparition des symptômes (20), tandis que les IgM neutralisent le SRAS-CoV-2 à la fois dans les tests de particules pseudovirales et les tests de séroneutralisation des plages de lyse (21).

On peut tirer des leçons de la longévité des anticorps contre le SRAS-CoV-2 en étudiant d'autres coronavirus humains, une stratégie qui a été examinée en détail ailleurs (22). Une récente étude systématique a mis en évidence la cinétique, les corrélations de protection et l'association des anticorps avec la gravité de la maladie parmi les coronavirus humains. En général, les réponses immunitaires contre d'autres coronavirus humains, comme le SRAS-CoV, le coronavirus du syndrome respiratoire du Moyen-Orient (MERS-CoV) et les coronavirus saisonniers, sont détectables un an après l'infection; dans certains cas, les anticorps peuvent persister plus longtemps (23). En outre, d'autres données suggèrent que les niveaux d'anticorps sériques sont restés relativement élevés deux ans après l'infection par le SRAS-CoV, et que jusqu'à $55 \%$ des patients avaient des anticorps détectables trois ans après I'infection (24). Cependant, aucun anticorps anti-SRAS-CoV détectable n'a été observé chez les patients six ans après I'infection (25). De même, il a été démontré que les anticorps contre le MERS-CoV persistaient pendant environ trois ans (26), bien que la persistance des anticorps anti-MERS-CoV dépende de la gravité de la maladie, puisque les patients atteints d'une maladie subclinique ou légère présentaient des taux $d$ 'anticorps faibles ou indétectables deux ans après l'infection (27). En revanche, des études de séroprévalence du coronavirus humain (HCoV)-229E et HCoV-OC43 ont porté à croire que le niveau des anticorps diminue de manière significative un an après l'infection (22). La persistance de la réponse immunitaire anti-SRAS-CoV-2 pour certaines populations doit être étudiée plus en profondeur, mais étant donné l'association du niveau des anticorps et de la gravité de la maladie (13), il est probable que la persistance des anticorps soit en corrélation avec la gravité de la maladie.

\section{Incidences de la gravité de la maladie et de l'âge}

Étant donné que de nombreuses infections par le SRAS-CoV-2 sont subcliniques ou asymptomatiques, il est essentiel de bien comprendre la réponse immunitaire (y compris les niveaux d'anticorps, la séroconversion et le délai de séronégativité) dans ces populations de patients. Il est désormais largement reconnu que les niveaux d'anticorps anti-SRAS-CoV-2 sont positivement associés à la gravité clinique de la maladie. Zhao et al. (10) ont été les premiers à signaler qu'un niveau d'anticorps totaux significativement plus élevé était indépendamment associé à une classification clinique plus mauvaise $(p=0,006)$ deux semaines après le début de la maladie. On a supposé qu'un niveau élevé d'anticorps totaux était un facteur de risque de maladie grave et qu'il pouvait même être utilisé comme marqueur de substitution pour un pronostic clinique plus défavorable. Une observation similaire a été faite chez 289 patients atteints de COVID-19 classés cliniquement comme ayant une infection légère, modérée ou grave. Les patients atteints d'une infection grave présentaient des taux d'lgA et d'lgG spécifiques dirigés contre le domaine $\mathrm{S} 1$ du spicule significativement plus élevé que ceux atteints d'une infection légère (28). De plus, ces lgG spécifiques étaient détectables après deux semaines chez seulement $20 \%$ des patients du groupe léger, par rapport à $100 \%$ des patients des groupes dont l'infection était grave ou modérée.

L'impact de la gravité de la maladie sur la cinétique de séroconversion et sa relation avec les propriétés neutralisantes dans le sérum n'est pas bien compris. Comparés aux patients présentant des symptômes légers, ceux présentant des symptômes graves avaient un délai significativement plus rapide pour la séroconversion lgG (médiane de 22 par rapport à 11 jours, respectivement). De plus environ $10 \%$ des patients présentant des symptômes légers n'avaient jamais eu de séroconversion (29). Des taux d'IgG détectables ont été observés plus de 75 jours après l'apparition des symptômes chez les patients montrant une séroconversion. Il est intéressant de noter que même 90 jours après l'apparition des symptômes, un petit nombre $(\mathrm{N}=3)$ de patients ont développé des niveaux $\mathrm{d}^{\prime}$ anticorps totaux inférieurs à la limite de détection des tests commerciaux, tout en ayant une réponse neutralisante détectable (gamme de dosage de 8-48). Cette observation est en contraste direct avec celle rapportée précédemment, où les sérums de $20 \%$ des patients ayant obtenu leur congé n'avaient aucune propriété neutralisante malgré les sérums de $100 \%$ des patients montrant une séroconversion (30). En outre, dans une petite étude, le développement des lgM chez les patients atteints de la maladie grave était retardé $(N=6$; huit jours) par rapport à ceux atteints d'une maladie légère ( $N=39$; six jours) (31). Jiang et al. (32) ont évalué les taux de séroconversion chez des patients symptomatiques, ainsi que chez des patients asymptomatiques, et ont conclu qu'il existe des cinétiques lgM/lgG différentes selon la gravité de la maladie. En effet, les auteurs ont rapporté que la séroconversion lgG s'est produite chez $94 \%$ des patients symptomatiques et $85 \%$ des patients asymptomatiques alors que la séroconversion IgM s'est produite chez $74 \%$ des patients symptomatiques et seulement chez $31 \%$ des patients asymptomatiques $(p<0,001)$. Fait intéressant, les auteurs ont également signalé que le délai médian de séroconversion (lgM ou lgG) dans le groupe asymptomatique était significativement plus court que dans le 
groupe symptomatique (délai médian de sept jours à partir du premier test positif de réaction en chaîne par polymérase par rapport à 14 jours; $p<0,001$ ).

Bien qu'il soit généralement admis que les anticorps persistent plus longtemps dans les cas graves de COVID-19, il existe une variation considérable entre les études, même lorsqu'elles sont normalisées pour la gravité clinique. Par exemple, les lgG dans les maladies légères à modérées semblent persister entre 3 et 5 mois $(14,33)$. Une étude évaluant des patients symptomatiques et asymptomatiques atteints de pneumonie associée à la COVID-19 (apparente ou subtile à la radiographie) a révélé que les anticorps étaient plus fréquemment détectés chez les patients symptomatiques (100\% par rapport à $71 \%$; mesure effectuée deux et cinq mois après l'apparition des symptômes) (34). En outre, les niveaux ont diminué de manière importante entre les deux points dans le temps. Une autre étude comparant les taux d'lgG et d'anticorps neutralisants chez des patients asymptomatiques et symptomatiques a montré que $40 \%$ des patients asymptomatiques sont devenus séronégatifs au début de la phase de convalescence (2 à 3 mois après l'apparition des symptômes), comparativement à seulement $12,9 \%$ des patients symptomatiques (35). Il est intéressant de noter que Choe et al. (36) ont également signalé que le dosage d'anticorps neutralisants était corrélé à la gravité de la maladie, ce qui suggère que les patients atteints d'une maladie grave peuvent être plus protégés contre la réinfection que les patients atteints d'une infection paucisymptomatique ou asymptomatique. II convient de faire remarquer qu'à ce jour, seuls quelques cas de réinfection ont été documentés (37-40), ce qui laisse penser que soit d'autres mécanismes immunitaires (tels que la réponse médiée par les lymphocytes T) peuvent contribuer à la protection contre la réinfection par le SRAS-CoV-2, soit, en raison de la courte période de circulation du SRAS-CoV-2 et de la mise en œuvre de restrictions de santé publique, il ne s'est pas encore écoulé suffisamment de temps pour que la réinfection soit détectée. De plus, comme la plupart de ces premières études ont examiné le niveau d'anticorps antinucléocapside, l'association de niveaux élevés d'anticorps avec un résultat clinique moins bon peut être liée à la production d'anticorps anti-nucléocapside plutôt qu'anti-spicule.

Bien qu'il y ait moins de données sur la relation entre l'âge et la réponse immunitaire dans le cas de la COVID-19, des données probantes récentes suggèrent qu'il pourrait y avoir des réponses immunitaires distinctes chez les enfants et les adultes. II a été démontré que, contrairement aux adultes, qui produisent des niveaux robustes d'anticorps anti-spicule et anti-nucléocapside ( $\mathrm{N})$, les enfants produisent moins $\mathrm{d}^{\prime}$ anticorps anti-N et neutralisants (41). La signification clinique de ce phénomène est inconnue, bien qu'il soit intéressant si l'on considère que la gravité de la maladie est positivement associée à l'âge.
La grande variabilité dans la façon dont la réponse immunitaire a été mesurée (i.e. différents tests, plateformes, méthodes et cibles antigéniques) rend difficiles les comparaisons directes entre les études. Malgré cette limitation, il est clair que tous les individus infectés ne produiront pas tous une réponse immunitaire et que le niveau d'anticorps peut diminuer avec le temps. Cela a des conséquences importantes pour I'interprétation des tests d'anticorps à des fins de diagnostic, notamment pour leur utilisation comme marqueur de substitution de l'immunité au SRAS-CoV-2. Dans le meilleur des cas, les anticorps anti-SRAS-CoV-2 ont une bonne concordance prédictive positive pour les propriétés neutralisantes; toutefois, la concordance prédictive négative est mauvaise.

\section{Comment mettre en œuvre les tests dans le laboratoire clinique}

La validation des tests d'anticorps pour les maladies infectieuses dépend souvent d'études visant à calculer la sensibilité et la spécificité diagnostiques (i.e. à corréler la réponse du test aux vrais positifs et aux vrais négatifs). Dans le cas du SRAS-CoV-2, cela est intrinsèquement difficile pour plusieurs raisons. Les données probantes portent à croire que la réponse humorale et la séropositivité qui en résulte sont affectées par la gravité de l'infection (présence/absence d'anticorps détectables), le temps écoulé depuis l'apparition des symptômes (longévité des anticorps) et l'antigène cible. De plus, comme la sensibilité du test de détection des acides ribonucléiques (ARN) viraux dépend du moment du prélèvement de l'échantillon au cours de la maladie et de la qualité de l'échantillon, les résultats sérologiques discordants sont souvent difficiles à interpréter pour la plupart des laboratoires cliniques qui n'ont pas accès aux tests de neutralisation. II est donc recommandé aux laboratoires cliniques de proposer des tests ayant fait l'objet d'un examen approfondi par un organisme de réglementation tel que Santé Canada ou la FDA, ou d'analyses de performance évaluées par des pairs, le cas échéant. II incombe au laboratoire clinique de s'assurer que les tests sérologiques sont utilisés comme prévu et répondent aux normes d'agrément locales.

La complexité et la portée des études de vérification interne requises pour que les laboratoires puissent proposer des tests sérologiques dépendent fortement de la méthode choisie. De nombreux laboratoires cliniques choisiront d'offrir des méthodes automatisées d'immunodosage par chimioluminescence en utilisant les instruments et l'infrastructure existants qui sont approuvés par Santé Canada ou la FDA pour une autorisation d'utilisation en urgence. Lorsque l'on utilise ces méthodologies validées, avec les caractéristiques de rendement fournies, une vérification modifiée de la méthode peut être acceptable avec une rigueur réduite des tests pour garantir que l'essai est adapté à l'objectif. Cependant, les modifications apportées à une méthode validée, comme l'utilisation d'un type d'échantillon différent (e.g. une tache de sang séché) ou la modification de la valeur seuil fixée par le fabricant, nécessitent une validation 
complète de la méthode avant de procéder à des tests sur des patients (les considérations relatives à la vérification et à la validation sont présentées dans le tableau 1). Dans le cas d'un test développé en laboratoire, une validation complète de la méthode est requise. Un diagramme détaillé décrivant d'autres scénarios possibles pour la validation et la vérification des méthodes a été publié précédemment (42).

Les vérifications de méthodes sont probablement la forme la plus courante d'évaluation de méthodes effectuée par les laboratoires cliniques à I'heure actuelle. Les laboratoires cliniques doivent

\section{Tableau 1 : Exigences minimales pour la validation et la vérification des essais qualitatifs}

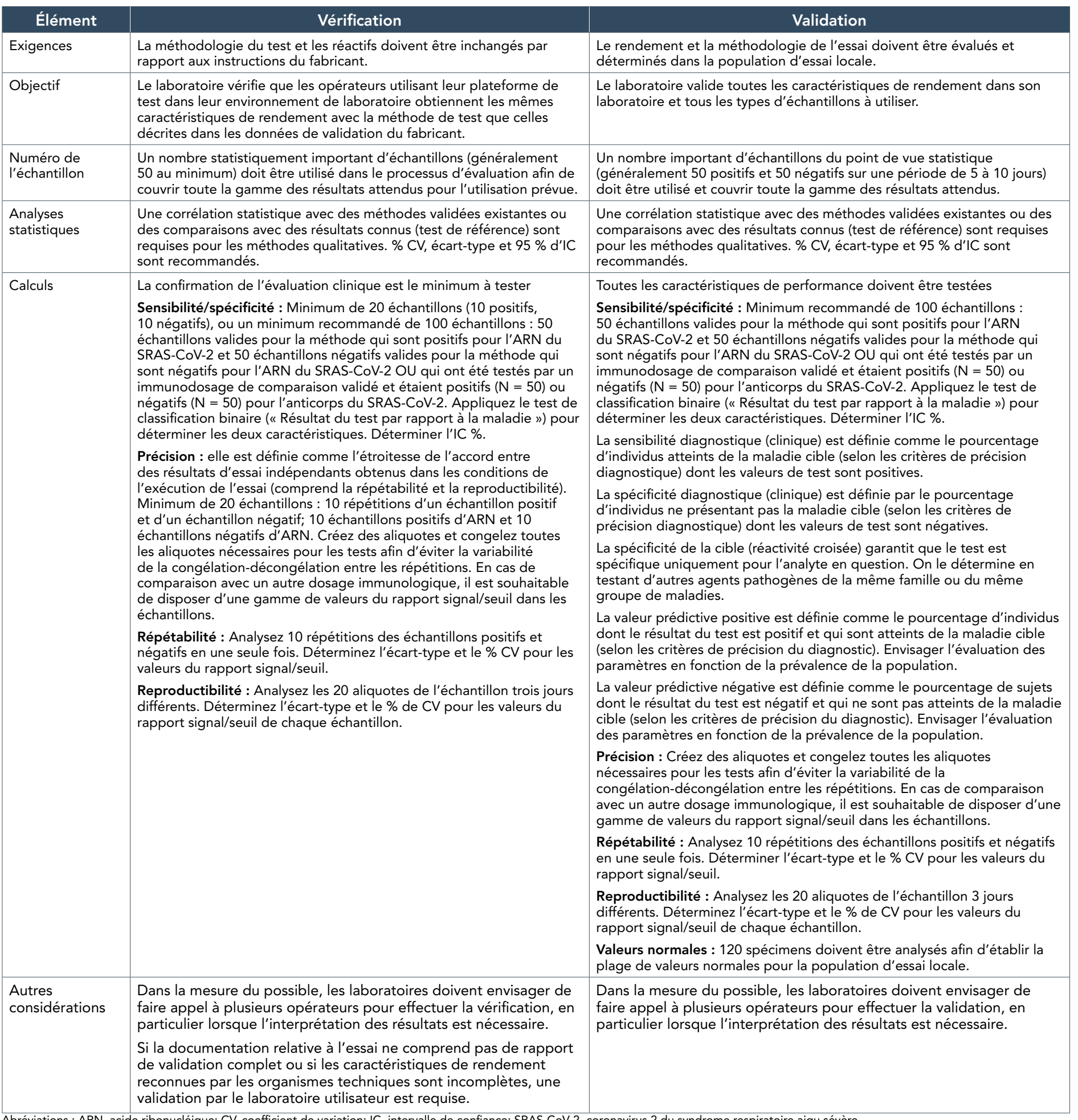

Abréviations : $A R N$, acide ribonucléique; $C V$, coefficient de variation; IC, intervalle de confiance; SRAS-CoV-2, coronavirus 2 du syndrome respiratoire aigu sévère 
Tableau 2 : Nombre théorique d'échantillons requis pour établir les sensibilité et spécificité diagnostiques estimées par marge d'erreur et intervalle de confiance

\begin{tabular}{|c|c|c|c|c|c|c|}
\hline \multirow{3}{*}{$\begin{array}{c}\text { Sensibilité } \\
\text { ou } \\
\text { spécificité } \\
\text { estimée }\end{array}$} & \multirow{2}{*}{\multicolumn{3}{|c|}{$\begin{array}{c}\text { Estimation avec une } \\
\text { erreur de } 2 \%\end{array}$}} & \multirow{2}{*}{\multicolumn{3}{|c|}{$\begin{array}{c}\text { Estimation avec une } \\
\text { erreur de } 5 \%\end{array}$}} \\
\hline & & & & & & \\
\hline & $90 \%$ & $95 \%$ & $99 \%$ & $90 \%$ & $95 \%$ & $99 \%$ \\
\hline $90 \%$ & 610 & 864 & 1493 & 98 & 138 & 239 \\
\hline $92 \%$ & 466 & 707 & 1221 & 75 & 113 & 195 \\
\hline $94 \%$ & 382 & 542 & 935 & 61 & 87 & 150 \\
\hline $95 \%$ & 372 & 456 & 788 & 60 & 73 & 126 \\
\hline $96 \%$ & 260 & 369 & 637 & 42 & 59 & 102 \\
\hline $97 \%$ & 197 & 279 & 483 & 32 & 45 & 77 \\
\hline $98 \%$ & 133 & 188 & 325 & 21 & 30 & 52 \\
\hline $99 \%$ & 67 & 95 & 164 & 11 & 15 & 26 \\
\hline
\end{tabular}

au moins vérifier les affirmations des fabricants en évaluant la sensibilité et la spécificité, la précision du test (reproductibilité), la réactivité croisée des anticorps non-SRAS-CoV-2 et les substances interférentes (telles que I'hémoglobine, les lipides ou la biotine) couramment trouvées dans leur population de patients. Un résumé des tailles minimales d'échantillon suggérées pour établir la sensibilité et la spécificité des épreuves diagnostiques est présenté dans le tableau 2. Le laboratoire clinique doit vérifier le rendement du test en utilisant des corrélations statistiques et des comparaisons fondées sur les déclarations du fabricant. Un examen minutieux est nécessaire en cas de résultats divergents, et les tests d'arbitrage peuvent être effectués par des laboratoires externes appliquant la même méthodologie. Si les échantillons de vérification proviennent d'une source locale, I'historique du patient peut être pris en compte pour réconcilier le rendement du test et pour caractériser davantage la population testée (patient externe, hospitalisé ou unité de soins intensifs, et moment des prélèvements). En outre, il peut être prudent d'interroger le signal obtenu à partir du test dans les positifs attendus qui peuvent être dans la gamme équivoque parce que le dosage des anticorps de certains patients peut avoir diminué au fil du temps, et les seuils du test ont été attribués avec seulement des échantillons limités. Un défi particulier lors de la vérification est de résoudre les résultats sérologiques faussement positifs soupçonnés étant donné la prévalence variable de la maladie (43). Les approches possibles pour résoudre les divergences comprennent l'analyse d'un autre test ou d'un autre antigène cible, l'examen des antécédents cliniques du patient, y compris le temps écoulé depuis l'apparition des symptômes et la recherche des contacts, ou l'examen des résultats antérieurs de I'analyse de I'ARN du SRAS-CoV-2.

\section{Prise en compte des algorithmes de test orthogonaux pour la sérologie du}

\section{coronavirus 2 du syndrome respiratoire aigu sévère}

En général, les laboratoires doivent s'efforcer d'utiliser des tests sérologiques dont la sensibilité, selon le fabricant, est supérieure à $95 \%$ et la spécificité supérieure à 99,5\% (1). Bon nombre des tests de détection des anticorps spécifiques du SRAS-CoV-2 dont l'utilisation est actuellement approuvée en Amérique du Nord répondent à ces critères de performance lorsqu'ils sont utilisés seuls (44-48). Cependant, lorsque le test est effectué dans des populations à faible prévalence ou chez des patients présentant une faible probabilité de maladie avant le test, la valeur prédictive positive ou la probabilité post-test seront inacceptablement faibles malgré une excellente spécificité. Par conséquent, les professionnels de laboratoire peuvent adopter une stratégie de test orthogonal pour améliorer la spécificité et les valeurs prédictives positives de l'interprétation des tests sérologiques pour le SRAS-CoV-2 (49-51). Dans le cadre d'un test orthogonal, les échantillons qui présentent un résultat positif ou équivoque lors d'un premier test sont testés à nouveau à l'aide d'un second test pour confirmer ou infirmer le résultat (1). Des stratégies de dépistage orthogonales ont été recommandées par les autorités de santé publique en Amérique du Nord dans les populations à faible prévalence $(1,52)$, et des protocoles détaillés sont disponibles (53). La plupart des méthodes de test orthogonal pour les anticorps anti-SRAS-CoV-2 impliquent deux tests indépendants, chacun ayant des caractéristiques de conception de test uniques telles que le type d'antigène (54-56) ou les formats de test (57). Toutefois, ces approches peuvent présenter des limites pratiques en termes de mise en œuvre, car l'épitope spécifique ciblé dans chaque test des fabricants est inconnu ou non fourni (58). II est également possible d'améliorer la sensibilité des méthodes de dépistage orthogonales en réduisant les valeurs seuils des tests commerciaux automatisés à haut débit pour le SRAS-CoV-2 (59); toutefois, la modification des recommandations du fabricant nécessite une validation complète des nouvelles valeurs seuils avant I'utilisation clinique.

Lorsque les utilisateurs envisagent un algorithme de test sérologique unique ou un algorithme de test en deux étapes (orthogonal), ils doivent tenir compte de l'objectif du test, de I'utilisation prévue des données générées et de la prévalence attendue du SRAS-CoV-2 dans la population concernée. Par exemple, I'utilisation de la sérologie pour le dépistage de cas cliniques particuliers (e.g. dans les cas de syndrome inflammatoire multiple chez l'enfant) ou dans les études séroépidémiologiques nécessite une sensibilité élevée du test et une valeur prédictive négative élevée dans les cas d'infection précoce (plus de deux semaines) et de convalescence tardive, respectivement. En effet, dans ces scénarios, le signalement des vrais cas devrait être la priorité; bien que les faux positifs ne soient pas souhaitables, ils peuvent être tolérés plus que les faux négatifs. Par exemple, dans les études séroépidémiologiques, un test sensible avec une bonne valeur prédictive positive est essentiel pour identifier les vrais cas afin de fournir des 
estimations robustes de la séropositivité au niveau de la population. En revanche, lors du dépistage des donneurs potentiels de plasma convalescent, la présence d'anticorps anti-SRAS-CoV-2 est essentielle (60), et une valeur prédictive positive supérieure à $99 \%$ devrait être exigée. Étant donné qu'une valeur prédictive négative élevée est moins importante dans ce scénario, le test orthogonal est recommandé à la fois pour les niveaux de prévalence faibles et élevés de la population (56). Ces exemples illustrent la nécessité d'envisager soigneusement des stratégies de test orthogonales adaptées à l'utilisation prévue des données sérologiques. En raison de ces différents scénarios, les stratégies de dépistage des anticorps anti-SRAS-CoV-2 varieront en fonction des exigences propres à chaque site.

\section{Essais sérologiques pour déterminer la puissance de neutralisation des anticorps du coronavirus 2 du syndrome respiratoire aigu sévère}

Pour mieux comprendre et caractériser l'immunité contre le SRAS-CoV-2 après une infection naturelle ou une vaccination, des tests fonctionnels tels que les tests de neutralisation du virus sont nécessaires. Les méthodes de référence précédentes/ actuelles pour détecter et quantifier les anticorps neutralisants du SRAS-CoV-2 ont utilisé des tests d'infection sur culture cellulaire, qui bloquent l'entrée du virus dans les cellules in vitro. Ces tests à virus vivant utilisent le virus du SRAS-CoV-2 de souche sauvage incubé avec des dilutions du sérum ou du plasma d'un patient. Le mélange est ensuite ajouté aux cellules sensibles pour déterminer si le sérum inhibe ou neutralise l'effet cytopathologique ou si une réduction des plaques est observée. Les tests de séroneutralisation par réduction de plaque permettent de quantifier les niveaux de neutralisation associés à l'échantillon clinique d'un individu. Cependant, les tests de virus vivants nécessitent un confinement de niveau de biosécurité 3, demandent beaucoup de travail et, en raison de la variation biologique associée à ces tests, il peut être difficile de les normaliser (61-63).

Les essais de neutralisation qui utilisent des virus pseudotypés, comme le virus de la stomatite vésiculaire ou les systèmes à base de lentivirus qui incorporent la protéine de pointe du SRAS-CoV-2, peuvent être utilisés dans les laboratoires de niveau de biosécurité 2 (64). Un exemple de procédure de base pour établir un test de pseudotype en utilisant des particules de lentivirus consiste à transfecter une lignée cellulaire " d'empaquetage ", comme les cellules HEK 293T, avec un certain nombre de plasmides pour produire des particules virales sûres et non réplicatives exprimant la protéine de spicule. Les plasmides transférés comprennent un plasmide exprimant un rapporteur, un plasmide codant pour le spicule du SRAS-CoV-2 et un certain nombre de plasmides codant pour des protéines lentivirales nécessaires à l'assemblage des particules virales. Les cellules transfectées produisent les virus pseudotypes, qui peuvent ensuite être utilisés pour infecter des cellules permissives exprimant le récepteur du SRAS-CoV-2, I'enzyme de conversion de l'angiotensine 2 (ECA2), afin de mesurer une diminution de l'effet cytopathique, par le biais du signal rapporteur, ou par la réduction des plages de lyseen présence du sérum du patient.

Bien que les formats de virus pseudotypés permettent d'alléger les contraintes de biosécurité, ils présentent les mêmes inconvénients que les tests de séroneutralisation par réduction de plaque classiques, à savoir qu'il est difficile de les normaliser d'un laboratoire à l'autre et que les caractéristiques du test peuvent varier en fonction des conditions de culture, des souches virales et des lignées cellulaires utilisées. En outre, ces tests cellulaires nécessitent un personnel hautement qualifié, ont un faible débit et des délais d'exécution sous-optimaux pour la prise de décision clinique. Ces inconvénients rendent la mise en œuvre de tests viraux pseudotypiques dans le laboratoire clinique peu pratique.

Récemment, plusieurs tests de neutralisation de substitution fondés sur le test ELISA qui détectent les anticorps ciblant le DLR ont été mis sur le marché (65-67). Ces tests plus rapides sont fondés sur le blocage, par des anticorps, de l'interaction entre le DLR du spicule et le récepteur cellulaire ECA2. La procédure de Abe et al. (67) utilise de l'ECA2 immobilisé et du DLR biotinylé soluble (qui a montré une sensibilité accrue par rapport à d'autres configurations de réactifs), et fournit une comparaison directe avec les tests ELISA classiques (détection d'anticorps qui se lient au DLR) dans un format de plaque.

Un certain nombre de tests commerciaux utilisant une plateforme similaire fondée sur le test ELISA sont également disponibles sur le site (e.g. GenScript cPass, Cayman SARS-CoV-2 antibody ELISA) qui mesurent indirectement et de manière semi-quantitative la capacité de neutralisation des anticorps dirigés contre le SRAS-CoV-2. La trousse GenScript de test de neutralisation virale de substitution (TNV) a été comparée avec des tests de neutralisation conventionnels à base de cellules (68-70) et a montré une bonne spécificité, et une sensibilité comparable aux tests basés sur la culture virale, mais a démontré une efficacité quelque peu réduite dans l'identification des échantillons avec un niveau inférieur de puissance de neutralisation virale. Cette observation peut s'expliquer par la détection spécifique des anticorps ciblant le DLR dans le test, car les anticorps neutralisants non-DLR ne sont pas ciblés dans les tests TNV. II convient également de noter que, contrairement aux tests de séroneutralisation par réduction de plaque fonctionnels ou aux tests cellulaires, les substituts peuvent détecter des anticorps non neutralisants dans certains échantillons. Cependant, l'avantage des TNV commerciaux et non commerciaux fondés sur le test ELISA est leur facilité d'utilisation et leur potentiel d'automatisation et de normalisation. De plus, avec des validations appropriées, ils peuvent être incorporés dans les algorithmes conventionnels de tests de neutralisation 
des virus et offrir un outil important pour évaluer la neutralisation dans les spécimens cliniques.

Une normalisation supplémentaire est en cours pour comparer les tests de neutralisation à base de cellules avec des tests de substitution utilisant des virus pseudotypés ou des tests de liaison compétitive sur la base du test ELISA (71). Une bonne corrélation a été observée entre un test de substitution modifié sur la base du test ELISA et une plateforme conventionnelle fondée sur des tests de séroneutralisation par réduction de plaque et un vecteur viral pseudotypé S (67). Les titres $d$ 'anticorps entre les tests de neutralisation TCID50 et les tests lentiviraux/de pseudotype du virus de la stomatite vésiculaire sont bien corrélés (71). Il convient de noter que, bien que les tests de neutralisation à base de cellules, tels que les tests de séroneutralisation par réduction de plaque ou les tests de micro-neutralisation, constituent les normes de référence pour la détection et la quantification des anticorps neutralisants dans les échantillons cliniques, la nature biologique de ces tests peut entraîner une certaine variabilité des niveaux et de la sensibilité lors de la comparaison des résultats entre les laboratoires (72). L'utilisation de panels de compétence composés d'échantillons de contrôle et de sérum/plasma de patients bien caractérisés facilite la normalisation entre les laboratoires.

Des tests sérologiques à haut débit disponibles dans le commerce, qui mesurent la liaison des anticorps à divers antigènes viraux, ont été directement comparés au niveau des anticorps de neutralisation dans des échantillons de patients à l'aide de tests de séroneutralisation par réduction de plaque ou TNV (73-75). Les résultats de ces comparaisons montrent que les tests sérologiques commerciaux sont sensibles pour la détection des anticorps totaux, mais sont moins robustes pour prédire le niveau de neutralisation par rapport aux tests conventionnels (e.g. tests de séroneutralisation par réduction de plaque) ou TNV. En outre, la fiabilité des platesformes commerciales à haut débit qui sont spécifiques aux antigènes protéiques de spicule/DLR pour déduire les équivalents de niveaux de neutralisation peut dépendre des délais de collecte des échantillons et des réponses spécifiques d'induction d'anticorps d'un individu. Cependant, des études plus récentes ont décrit une forte corrélation entre les concentrations d'anticorps anti-DLR et les titres d'anticorps inhibiteurs de la protéine S/DLR-ECA2 ( $r>0,86, p<0,001)(76,77)$, avec la possibilité que les anticorps anti-nucléocapsides (signal à la coupure supérieur ou égal à 5,0 ) servent de substitut pour le dépistage du plasma à titre élevé d'anticorps neutralisants (supérieur ou égal à 160) (78).

\section{Détection des anticorps dérivés de la vaccination par rapport à l'infection naturelle}

Avec le déploiement des vaccins contre le SRAS-CoV-2, la détection et la quantification des anticorps induits par le vaccin par les tests commerciaux actuels doivent être vérifiées par rapport à la détection de l'immunité naturelle après l'infection. Une différence dans la capacité à détecter les anticorps provenant à la fois d'une infection naturelle et d'une vaccination a été observée avec d'autres infections virales, notamment le virus varicelle-zona, où les tests commerciaux peuvent facilement détecter les anticorps lgG chez les personnes ayant eu une infection naturelle, mais où de nombreux tests commerciaux sont moins robustes pour détecter les anticorps induits par la vaccination (79). De multiples études sont en cours pour déterminer quels anticorps anti-SRAS-CoV-2 sont détectés par les tests commerciaux, et s'il existe des variations dans la détection en fonction du type de vaccin reçu par un individu. En raison du manque actuel de sérum provenant de personnes vaccinées, il est difficile pour un laboratoire clinique d'intégrer des algorithmes de sérologie appropriés, d'autant plus que les cibles des vaccins et des tests de laboratoire sont exclusives. De plus, avec l'émergence de nouveaux vaccins candidats, la variabilité du type de vaccin et de l'antigène peut limiter la capacité des tests de sérologie anti-SRAS-CoV-2 commerciaux actuels à déterminer si un patient a été vacciné. En outre, rien ne prouve que la présence et le niveau des anticorps anti-SRASCoV-2 puissent être extrapolés au statut immunitaire des patients vaccinés.

Le rôle de la différenciation des anticorps dérivés de l'infection naturelle par rapport aux anticorps induits par le vaccin n'a pas d'importance pour la gestion clinique, et il n'existe actuellement aucun test anti-SRAS-CoV-2 approuvé par Santé Canada et spécifique aux populations vaccinées. Au cours des quatre premiers mois suivant la vaccination, il est probable que les anticorps naturels et ceux induits par le vaccin puissent être différenciés en utilisant une combinaison de tests anti-nucléocapside et anti-spicule. Au Canada, par exemple, où seuls les vaccins à base de spicule sont actuellement utilisés, un anti-nucléocapside positif pourrait indiquer une infection naturelle, et un anti-nucléocapside négatif mais un anti-spicule positif pourrait indiquer des anticorps induits par le vaccin. Cependant, ce processus n'est pas simple car des profils $d$ 'anticorps anti-nucléocapside négatifs mais positifs ont été identifiés chez les personnes ayant suivi une infection naturelle (les anticorps anti-spicule persistent plus longtemps que les anticorps anti-nucléocapside $(50,80))$. Le paysage se complique après quatre mois ou plus, car les anticorps anti-nucléocapsides sont censés diminuer chez les patients qui se sont rétablis après une infection naturelle. Par conséquent, les tests actuels ne peuvent pas déterminer si un patient avait des anticorps antispicule positifs et des anticorps anti-nucléocapside négatifs en raison d'un antécédent d'infection ou d'une vaccination. Du point de vue de la santé publique, il est important de comprendre l'immunité globale d'une population, et le fait que l'immunité soit dérivée d'un vaccin ou d'une infection naturelle est académique. Dans les juridictions n'utilisant que des vaccins à base de spicules, l'utilisation des tests de spicules ou de domaine de liaison aux récepteurs doit être envisagée comme cible principale du dépistage afin de s'assurer que les deux scénarios sont détectés dans les études de surveillance. À I'inverse, la présence d'anticorps induits par la vaccination peut être problématique pour les tests cliniques, par exemple pour 
le diagnostic du syndrome inflammatoire multiple chez l'enfant. Ainsi, les tests sérologiques cliniques ne sont pas recommandés pour les personnes ayant reçu le vaccin COVID-19, surtout si un test qui détecte les anticorps anti- $\mathrm{N}$ n'est pas disponible. II faut de meilleurs marqueurs de l'état immunitaire, qui soient simples, reproductibles et robustes.

L'utilisation de la sérologie pour déterminer l'immunité est un défi. II n'existe actuellement aucun test disponible dans le commerce pour déterminer l'état immunitaire, qui ne peut être évalué qu'à l'aide des tests de séroneutralisation par réduction de plaque. En l'absence d'une norme universelle ou d'un marqueur de substitution de l'immunité, la détection d'anticorps dans les tests sérologiques, quelle que soit l'intensité du signal, ne permet pas de déterminer avec certitude si un individu est susceptible à une infection par le SRAS-CoV-2 ou immunisé contre celle-ci. Par conséquent, la valeur d'un "passeport d'immunité", dans lequel les personnes ayant des anticorps détectables ont moins de restrictions en matière de santé publique, est limitée et peut nuire aux efforts de santé publique visant à réduire la propagation de l'infection.

Vers la fin de 2020, une série de variants préoccupants du SRAS-CoV-2 sont apparus dans différentes régions géographiques du monde, comme le Royaume-Uni, I'Afrique du Sud et le Brésil (81). Ces variants comprennent des mutations spécifiques au sein de la protéine $S$ (K417N, E484K, N501Y) qui sont partagées entre toutes les lignées de variants indépendants (82). La préoccupation la plus pressante concernant ces variants est la transmissibilité accrue (83) qui leur est associée; mais l'aspect d'échappement immunitaire, avec le potentiel d'échapper à la détection et donc au diagnostic, est également troublant. Il a été démontré que ces mutations affectaient les propriétés de neutralisation selon que les anticorps monoclonaux ou polyclonaux étaient testés (8486). En outre, le variant P.1 trouvé pour la première fois en circulation à Manaus, au Brésil, a été associé à une réinfection chez des personnes immunocompétentes (87), ce qui rendrait probablement plus difficile l'interprétation des résultats des tests de sérologie et de tests de séroneutralisation par réduction de plaque ciblant le virus de souche sauvage ou les antigènes viraux.

Actuellement, il n'y a pas de recommandation pour le dépistage de l'immunité pré ou post-vaccinale (88), car il n'y a pas de corrélation entre la détection des anticorps et l'immunité à l'infection, et peu de travaux ont été réalisés pour comprendre la production d'anticorps dans les populations immunodéprimées. Pour comprendre quel niveau d'anticorps pourrait être corrélé à I'immunité contre l'infection, des études plus approfondies sont nécessaires, notamment la création d'une norme internationale permettant de comparer les niveaux d'anticorps entre différents vaccins, tests et laboratoires.

\section{Conclusion}

La mise en œuvre de la sérologie SRAS-CoV-2 dans le laboratoire clinique est un défi, et les professionnels de laboratoire doivent être conscients des limites de ces tests. II existe un certain nombre de facteurs inconnus qui affectent ces tests, et les directives et recommandations pour leur utilisation dans les laboratoires cliniques sont en constante évolution. Nous présentons ici les recommandations les plus récentes en matière de dépistage au Canada et fournissons des conseils pratiques aux laboratoires pour qu'ils choisissent les tests sérologiques appropriés et utilisent les meilleurs algorithmes de dépistage pour leurs populations locales.

\section{Déclaration des auteurs}

C. L. C. - Conceptualisation du projet, version originale, révision du manuscrit, édition finale du manuscrit

J. N. K., V. T., J. V. K., J. G., C. O., J. L. R., M. D., T. H., D. R. S., A. L., L. J., P. N. L., H. W., C. T., L. R. L., M. M., J. D. F., A. D. Conception du projet, version originale, révision du manuscrit N. E. - Révision du manuscrit, coordination des ébauches

Tous les auteurs ont approuvé la version finale envoyée pour publication et sont responsables de tous les aspects du travail.

\section{Intérêts concurrents}

Aucun.

\section{Remerciements}

Le Dr J. Kanji travaille actuellement à la Division des maladies infectieuses, Département de médecine, Université de Calgary, Calgary, Alberta.

\section{Financement}

Aucun.

\section{Références}

1. Van Caeseele P, Bailey D, Forgie SE, Dingle TC, Krajden M; Canadian Public Health Laboratory Network; Canadian Society of Clinical Chemists; Association of Medical Microbiology and Infectious Disease Canada; Canadian Association for Clinical Microbiology and Infectious Diseases; COVID-19 Immunity Task Force. SARS-CoV-2 (COVID-19) serology: implications for clinical practice, laboratory medicine and public health. CMAJ 2020;192(34):E973-9. DOl PubMed

2. Charlton CL, Kanji JN, Johal K, Bailey A, Plitt SS, MacDonald C, Kunst A, Buss E, Burnes LE, Fonseca K, Berenger BM, Schnabl K, Hu J, Stokes W, Zelyas N, Tipples G. Evaluation of Six Commercial Mid- to High-Volume Antibody and Six Point-of-Care Lateral Flow Assays for Detection of SARS-CoV-2 Antibodies. J Clin Microbiol 2020;58(10):e01361-20. DOI PubMed 
3. Grzelak L, Temmam S, Planchais C, Demeret C, Tondeur L, Huon C, Guivel-Benhassine F, Staropoli I, Chazal M, Dufloo J, Planas D, Buchrieser J, Rajah MM, Robinot R, Porrot F, Albert M, Chen KY, Crescenzo-Chaigne B, Donati F, Anna F, Souque $P$, Gransagne M, Bellalou J, Nowakowski M, Backovic M, Bouadma L, Le Fevre L, Le Hingrat Q, Descamps D, Pourbaix A, Laouénan C, Ghosn J, Yazdanpanah Y, Besombes C, Jolly N, Pellerin-Fernandes S, Cheny O, Ungeheuer MN, Mellon G, Morel P, Rolland S, Rey FA, Behillil S, Enouf V, Lemaitre A, Créach MA, Petres $S$, Escriou N, Charneau P, Fontanet A, Hoen B, Bruel T, Eloit M, Mouquet H, Schwartz O, van der Werf S. A comparison of four serological assays for detecting anti-SARS-CoV-2 antibodies in human serum samples from different populations. Sci Transl Med 2020;12(559):eabc3103. DOI PubMed

4. Lee CY, Lin RT, Renia L, Ng LF. Serological Approaches for COVID-19: Epidemiologic Perspective on Surveillance and Control. Front Immunol 2020;11:879. DOI PubMed

5. Centers for Disease Control and Prevention. Information for Healthcare Providers about Multisystem Inflammatory Syndrome in Children (MIS-C). Atlanta (GA): CDC; 2021.

https://www.cdc.gov/mis-c/hcp/index.html

6. World Health Organization. Manual for the Laboratory-based Surveillance of Measles, Rubella, and Congenital Rubella Syndrome. Third Edition Edition. WHO: June 2018.

https://www.who.int/immunization/monitoring_surveillance/ burden/laboratory/manual/en/

7. Agence de la santé publique du Canada. L'élimination de la rougeole, de la rubéole et du syndrome de rubéole congénitale au Canada : Rapport de documentation et de vérification. ASPC; 2011. https://www.canada.ca/fr/sante-publique/services/ immunisation/maladies-pouvant-etre-prevenues-vaccination/ elimination-rougeole-rubeole-syndrome-rubeole-congenitalecanada.html

8. Grzelak L, Temmans S, Planchais S, Demeret C, Huon C, Guivel-Benhassine F, Staropoli I, Chazal M, Dufloo J, Planas D, Buchrieser J, Rajah MM, Robinot R, Porrot F, Albert M, Chen K-Y, Crescenzo B, Donati F, Anna F, Souque F, Gransagne M, Bellalou J, Nowakowski M, Backovic M, Bouadma L, Le Fevre L, Le Hingrat Q, Descamps D, Pourbaix A, Yazdanpanah $Y$, Tondeur L, Besombes C, Ungeheuer M-N, Mellon G, Morel P, Rolland S, Rey F, Behillil S, Enouf V, Lemaitre A, Créach M-A, Petres S, Escriou N, Charneau P, Fontanet A, Hoen B, Bruel T, Eloit M, Mouquet H, Schwartz O, van der Werf S. SARS-CoV-2 serological analysis of COVID-19 hospitalized patients, pauci-symptomatic individuals and blood donors. medRxiv. 2020.04.21.20068858. DOI

9. Long $Q X$, Liu BZ, Deng HJ, Wu GC, Deng $K$, Chen $Y K$, Liao $P_{1}$ Qiu JF, Lin Y, Cai XF, Wang DQ, Hu Y, Ren JH, Tang N, Xu YY, Yu LH, Mo Z, Gong F, Zhang XL, Tian WG, Hu L, Zhang XX, Xiang JL, Du HX, Liu HW, Lang CH, Luo XH, Wu SB, Cui XP, Zhou Z, Zhu MM, Wang J, Xue CJ, Li XF, Wang L, Li ZJ, Wang K, Niu CC, Yang QJ, Tang XJ, Zhang Y, Liu XM, Li JJ, Zhang DC, Zhang F, Liu P, Yuan J, Li Q, Hu JL, Chen J, Huang AL. Antibody responses to SARS-CoV-2 in patients with COVID-19. Nat Med 2020;26(6):845-8. DOI PubMed

10. Zhao J, Yuan $Q$, Wang $H$, Liu W, Liao $X$, Su Y, Wang $X$, Yuan J, Li T, Li J, Qian S, Hong C, Wang F, Liu Y, Wang Z, He Q, Li Z, He B, Zhang T, Fu Y, Ge S, Liu L, Zhang J, Xia N, Zhang Z. Antibody Responses to SARS-CoV-2 in Patients With Novel Coronavirus Disease 2019. Clin Infect Dis 2020;71(16):2027-34. DOI PubMed
11. Guo $L$, Ren $L$, Yang $S$, Xiao M, Chang D, Yang F, Dela Cruz CS, Wang Y, Wu C, Xiao Y, Zhang L, Han L, Dang S, Xu Y, Yang OW, Xu SY, Zhu HD, Xu YC, Jin Q, Sharma L, Wang L, Wang J. Profiling Early Humoral Response to Diagnose Novel Coronavirus Disease (COVID-19). Clin Infect Dis 2020;71(15):778-85. DOI PubMed

12. Suhandynata RT, Hoffman MA, Kelner MJ, McLawhon RW, Reed SL, Fitzgerald RL. Longitudinal Monitoring of SARS-CoV-2 IgM and IgG Seropositivity to Detect COVID-19. J Appl Lab Med 2020;5(5):908-20. DOI PubMed

13. Seow J, Graham C, Merrick B, Acors S, Pickering S, Steel KJ, Hemmings O, O'Byrne A, Kouphou N, Galao RP, Betancor G, Wilson HD, Signell AW, Winstone H, Kerridge C, Huettner I, Jimenez-Guardeño JM, Lista MJ, Temperton N, Snell LB, Bisnauthsing K, Moore A, Green A, Martinez L, Stokes B, Honey J, Izquierdo-Barras A, Arbane G, Patel A, Tan MK, O'Connell L, O'Hara G, MacMahon E, Douthwaite S, Nebbia G, Batra R, Martinez-Nunez R, Shankar-Hari M, Edgeworth JD, Neil SJ, Malim MH, Doores KJ. Longitudinal observation and decline of neutralizing antibody responses in the three months following SARS-CoV-2 infection in humans. Nat Microbiol 2020;5(12):1598-607. DOI PubMed

14. Wajnberg A, Amanat F, Firpo A, Altman DR, Bailey MJ, Mansour M, McMahon M, Meade P, Mendu DR, Muellers K, Stadlbauer D, Stone K, Strohmeier S, Simon V, Aberg J, Reich DL, Krammer F, Cordon-Cardo C. Robust neutralizing antibodies to SARS-CoV-2 infection persist for months. Science 2020;370(6521):1227-30. DOI PubMed

15. Ripperger TJ, Uhrlaub JL, Watanabe $M$, Wong $R$, Castaneda $Y$, Pizzato HA, Thompson MR, Bradshaw C, Weinkauf CC, Bime C, Erickson HL, Knox K, Bixby B, Parthasarathy S, Chaudhary S, Natt B, Cristan E, El Aini T, Rischard F, Campion J, Chopra M, Insel M, Sam A, Knepler JL, Capaldi AP, Spier CM, Dake MD, Edwards T, Kaplan ME, Scott SJ, Hypes C, Mosier J, Harris DT, LaFleur BJ, Sprissler R, Nikolich-Žugich J, Bhattacharya D. Orthogonal SARS-CoV-2 Serological Assays Enable Surveillance of Low-Prevalence Communities and Reveal Durable Humoral Immunity. Immunity 2020;53(5):925-933.e4. DOI PubMed

16. Lau EH, Tsang OT, Hui DS, Kwan MY, Chan WH, Chiu SS, Ko RL, Chan KH, Cheng SM, Perera RA, Cowling BJ, Poon LL, Peiris M. Neutralizing antibody titres in SARS-CoV-2 infections. Nat Commun 2021;12(1):63. DOI PubMed

17. Hartley GE, Edwards ES, Aui PM, Varese N, Stojanovic S, McMahon J, Peleg AY, Boo I, Drummer HE, Hogarth PM, O'Hehir RE, van Zelm MC. Rapid generation of durable $B$ cell memory to SARS-CoV-2 spike and nucleocapsid proteins in COVID-19 and convalescence. Sci Immunol 2020;5(54):eabf8891. DOI PubMed

18. Isho $B$, Abe KT, Zuo M, Jamal AJ, Rathod B, Wang JH, Li Z, Chao G, Rojas OL, Bang YM, Pu A, Christie-Holmes N, Gervais C, Ceccarelli D, Samavarchi-Tehrani P, Guvenc F, Budylowski P, Li A, Paterson A, Yue FY, Marin LM, Caldwell L, Wrana JL, Colwill K, Sicheri F, Mubareka S, Gray-Owen SD, Drews SJ, Siqueira WL, Barrios-Rodiles M, Ostrowski M, Rini JM, Durocher Y, McGeer AJ, Gommerman JL, Gingras AC. Persistence of serum and saliva antibody responses to SARS-CoV-2 spike antigens in COVID-19 patients. Sci Immunol 2020;5(52):eabe5511. PubMed

19. Maine GN, Lao KM, Krishnan SM, Afolayan-Oloye O, Fatemi S, Kumar S, VanHorn L, Hurand A, Sykes E, Sun Q. Longitudinal characterization of the $\operatorname{lgM}$ and $\lg G$ humoral response in symptomatic COVID-19 patients using the Abbott Architect. J Clin Virol 2020;133:104663. DOI PubMed 
20. Sterlin D, Mathian A, Miyara M, Mohr A, Anna F, Claër L, Quentric P, Fadlallah J, Devilliers H, Ghillani P, Gunn C, Hockett R, Mudumba S, Guihot A, Luyt CE, Mayaux J, Beurton A, Fourati S, Bruel T, Schwartz O, Lacorte JM, Yssel H, Parizot C, Dorgham K, Charneau P, Amoura Z, Gorochov G. IgA dominates the early neutralizing antibody response to SARS-CoV-2. Sci Transl Med 2021;13(577):eabd2223. DOI PubMed

21. Gasser R, Cloutier M, Prévost J, Fink C, Ducas É, Ding S, Dussault N, Landry P, Tremblay T, Laforce-Lavoie A, Lewin A, Beaudoin-Bussières $G$, Laumaea $A$, Medjahed $H$, Larochelle $C$, Richard J, Dekaban GA, Dikeakos JD, Bazin R, Finzi A. Major role of IgM in the neutralizing activity of convalescent plasma against SARS-CoV-2. Cell Rep 2021;34(9):108790. DOI PubMed

22. Sariol A, Perlman S. Lessons for COVID-19 Immunity from Other Coronavirus Infections. Immunity 2020;53(2):248-63. DOI PubMed

23. Huang AT, Garcia-Carreras $B$, Hitchings MD, Yang $B$, Katzelnick LC, Rattigan SM, Borgert BA, Moreno CA, Solomon BD, Trimmer-Smith L, Etienne V, Rodriguez-Barraquer I, Lessler J, Salje H, Burke DS, Wesolowski A, Cummings DA. A systematic review of antibody mediated immunity to coronaviruses: kinetics, correlates of protection, and association with severity. Nat Commun 2020;11(1):4704. DOI PubMed

24. Wu LP, Wang NC, Chang YH, Tian XY, Na DY, Zhang LY, Zheng L, Lan T, Wang LF, Liang GD. Duration of antibody responses after severe acute respiratory syndrome. Emerg Infect Dis 2007;13(10):1562-4. DOI PubMed

25. Tang F, Quan Y, Xin ZT, Wrammert J, Ma MJ, Lv H, Wang TB, Yang H, Richardus JH, Liu W, Cao WC. Lack of peripheral memory $B$ cell responses in recovered patients with severe acute respiratory syndrome: a six-year follow-up study. J Immunol 2011;186(12):7264-8. DOI PubMed

26. Payne DC, Iblan I, Rha B, Alqasrawi S, Haddadin A, AI Nsour M, Alsanouri T, Ali SS, Harcourt J, Miao C, Tamin A, Gerber SI, Haynes LM, Al Abdallat MM. Persistence of Antibodies against Middle East Respiratory Syndrome Coronavirus. Emerg Infect Dis 2016;22(10):1824-6. DOI PubMed

27. Zhao J, Alshukairi AN, Baharoon SA, Ahmed WA, Bokhari AA, Nehdi AM, Layqah LA, Alghamdi MG, Al Gethamy MM, Dada AM, Khalid I, Boujelal M, Al Johani SM, Vogel L, Subbarao K, Mangalam A, Wu C, Ten Eyck P, Perlman $\mathrm{S}$, Zhao J. Recovery from the Middle East respiratory syndrome is associated with antibody and T-cell responses. Sci Immunol 2017;2(14):eaan5393. DOI PubMed

28. Kowitdamrong E, Puthanakit $T$, Jantarabenjakul W, Prompetchara E, Suchartlikitwong P, Putcharoen O, Hirankarn N, Putcharoen O, Hirankarn N. Antibody responses to SARS-CoV-2 in patients with differing severities of coronavirus disease 2019. PLoS One 2020;15(10):e0240502. DOI PubMed

29. Marklund $E$, Leach $S$, Axelsson $H$, Nyström $K$, Norder $H$, Bemark $M$, Angeletti $D$, Lundgren A, Nilsson $S$, Andersson LM, Yilmaz A, Lindh M, Liljeqvist JÅ, Gisslén M. Serum-lgG responses to SARS-CoV-2 after mild and severe COVID-19 infection and analysis of IgG non-responders. PLoS One 2020;15(10):e0241104. DOl PubMed
30. Kalkan Yazıcı M, Koç MM, Çetin NS, Karaaslan E, Okay G, Durdu B, Sümbül B, Doymaz MZ. Discordance between Serum Neutralizing Antibody Titers and the Recovery from COVID-19. J Immunol 2020;205(10):2719-25. DOI PubMed

31. Shen L, Wang C, Zhao J, Tang $X$, Shen Y, Lu M, Ding Z, Huang C, Zhang J, Li S, Lan J, Wong G, Zhu Y. Delayed specific IgM antibody responses observed among COVID-19 patients with severe progression. Emerg Microbes Infect 2020;9(1):1096-101. DOI PubMed

32. Jiang $C$, Wang $Y$, Hu M, Wen $L$, Wen $C$, Wang $Y$, Zhu W, Tai $S$, Jiang Z, Xiao K, Faria NR, De Clercq E, Xu J, Li G. Antibody seroconversion in asymptomatic and symptomatic patients infected with severe acute respiratory syndrome coronavirus 2 (SARS-CoV-2). Clin Transl Immunology 2020;9(9):e1182. DOI PubMed

33. Ibarrondo FJ, Fulcher JA, Goodman-Meza D, Elliott J, Hofmann C, Hausner MA, Ferbas KG, Tobin NH, Aldrovandi GM, Yang OO. Rapid Decay of Anti-SARS-CoV-2 Antibodies in Persons with Mild Covid-19. N Engl J Med 2020;383(11):1085-7. DOI PubMed

34. Choe PG, Kang CK, Suh HJ, Jung J, Song KH, Bang JH, Kim ES, Kim HB, Park SW, Kim NJ, Park WB, Oh MD. Waning Antibody Responses in Asymptomatic and Symptomatic SARS-CoV-2 Infection. Emerg Infect Dis 2021;27(1):327-9. DOI PubMed

35. Long QX, Tang XJ, Shi QL, Li Q, Deng HJ, Yuan J, Hu JL, Xu W, Zhang Y, Lv FJ, Su K, Zhang F, Gong J, Wu B, Liu XM, Li JJ, Qiu JF, Chen J, Huang AL. Clinical and immunological assessment of asymptomatic SARS-CoV-2 infections. Nat Med 2020;26(8):1200-4. DOI PubMed

36. Choe PG, Kang CK, Suh HJ, Jung J, Kang E, Lee SY, Song KH, Kim HB, Kim NJ, Park WB, Kim ES, Oh MD. Antibody Responses to SARS-CoV-2 at 8 Weeks Postinfection in Asymptomatic Patients. Emerg Infect Dis 2020;26(10):2484-7. DOI PubMed

37. Tillett RL, Sevinsky JR, Hartley PD, Kerwin H, Crawford N, Gorzalski A, Laverdure C, Verma SC, Rossetto CC, Jackson D, Farrell MJ, Van Hooser S, Pandori M. Genomic evidence for reinfection with SARS-CoV-2: a case study. Lancet Infect Dis 2021;21(1):52-8. DOI PubMed

38. To KK, Hung IF, Ip JD, Chu AW, Chan WM, Tam AR, Fong CH, Yuan S, Tsoi HW, Ng AC, Lee LL, Wan P, Tso E, To WK, Tsang D, Chan KH, Huang JD, Kok KH, Cheng VC, Yuen KY. COVID-19 re-infection by a phylogenetically distinct SARS-coronavirus-2 strain confirmed by whole genome sequencing. Clin Infect Dis 2020;ciaa1275. (Publié en ligne avant impression). DOI PubMed

39. Van Elslande J, Vermeersch P, Vandervoort K, Wawina-Bokalanga T, Vanmechelen B, Wollants E, Laenen L, André E, Van Ranst M, Lagrou K, Maes P. Symptomatic SARS-CoV-2 reinfection by a phylogenetically distinct strain. Clin Infect Dis 2020; ciaa1330. (Publié en ligne avant impression). DOI PubMed

40. Prado-Vivar $B$, Becerra-Wong $M$, Guadalupe JJ, Márquez $S$, Gutierrez B, Rojas-Silva P, Grunauer M, Treuba G, Barragan V, Cardenas P. A case of SARS-CoV-2 reinfection in Ecuador. Lancet Infect Dis 2020. (Publié en ligne avant impression). DOI 
41. Weisberg SP, Connors TJ, Zhu Y, Baldwin MR, Lin WH, Wontakal S, Szabo PA, Wells SB, Dogra P, Gray J, Idzikowski E, Stelitano D, Bovier FT, Davis-Porada J, Matsumoto R, Poon MM, Chait M, Mathieu C, Horvat B, Decimo D, Hudson KE, Zotti FD, Bitan ZC, La Carpia F, Ferrara SA, Mace E, Milner J, Moscona A, Hod E, Porotto M, Farber DL. Distinct antibody responses to SARS-CoV-2 in children and adults across the COVID-19 clinical spectrum. Nat Immunol 2021;22(1):25-31. DOI PubMed

42. National Association of Testing Authorities. Australia (NATA). General Accreditation Guidance - Validation and verification of quantitative and qualitative test methods. Australia: NATA; 2018. https://www.nata.com.au/phocadownload/ gen-accreditation-guidance/Validation-and-Verification-o f-Quantitative-and-Qualitative-Test-Methods.pdf

43. Farnsworth CW, Anderson NW. SARS-CoV-2 Serology: Much Hype, Little Data. Clin Chem 2020;66(7):875-7. DOI PubMed

44. Kohmer N, Westhaus S, Rühl C, Ciesek S, Rabenau HF. Brief clinical evaluation of six high-throughput SARS-CoV-2 lgG antibody assays. J Clin Virol 2020;129:104480. DOI PubMed

45. Manthei DM, Whalen JF, Schroeder LF, Sinay AM, Li SH, Valdez R, Giacherio DA, Gherasim C. Differences in Performance Characteristics Among Four High-Throughput Assays for the Detection of Antibodies Against SARS-CoV-2 Using a Common Set of Patient Samples. Am J Clin Pathol 2021;155(2):267-79. DOI PubMed

46. Merrill AE, Jackson JB, Ehlers A, Voss D, Krasowski MD. Head-to-Head Comparison of Two SARS-CoV-2 Serology Assays. J Appl Lab Med 2020;5(6):1351-7. DOI PubMed

47. Perkmann T, Perkmann-Nagele N, Breyer MK, Breyer-Kohansal R, Burghuber OC, Hartl S, Aletaha D, Sieghart D, Quehenberger P, Marculescu R, Mucher P, Strassl R, Wagner OF, Binder CJ, Haslacher H. Side-by-Side Comparison of Three Fully Automated SARS-CoV-2 Antibody Assays with a Focus on Specificity. Clin Chem 2020;66(11):1405-13. DOI PubMed

48. Prince HE, Givens TS, Lapé-Nixon M, Clarke NJ, Schwab DA, Batterman HJ, Jones RS, Meyer WA 3rd, Kapoor H, Rowland CM, Haji-Sheikhi F, Marlowe EM. Detection of SARS-CoV-2 lgG Targeting Nucleocapsid or Spike Protein by Four High-Throughput Immunoassays Authorized for Emergency Use. J Clin Microbiol 2020;58(11):e01742-20. DOI PubMed

49. Pflüger LS, Bannasch JH, Brehm TT, Pfefferle $S$, Hoffmann A, Nörz D, van der Meirschen M, Kluge S, Haddad M, Pischke S, Hiller J, Addo MM, Lohse AW, Schulze Zur Wiesch J, Peine S, Aepfelbacher M, Lütgehetmann M. Clinical evaluation of five different automated SARS-CoV-2 serology assays in a cohort of hospitalized COVID-19 patients. J Clin Virol 2020;130:104549. DOI PubMed

50. Ripperger TJ, Uhrlaub JL, Watanabe $M$, Wong R, Castaneda $Y$, Pizzato HA, Thompson MR, Bradshaw C, Weinkauf CC, Bime C, Erickson HL, Knox K, Bixby B, Parthasarathy S, Chaudhary S, Natt B, Cristan E, T El Aini, Rischard F, Campion J, Chopra M, Insel M, Sam A, Knepler JL, Capaldi AP, Spier CM, Dake MD, Edwards T, Kaplan ME, Scott SJ, Hypes C, Mosier J, Harris DT, LaFleur BJ, Sprissler R, Nikolich-Žugic J, Bhattacharya D. Detection, prevalence, and duration of humoral responses to SARS-CoV-2 under conditions of limited population exposure. medRxiv. 2020. (Publié en ligne avant impression). DOI
51. Xu G, Emanuel AJ, Nadig S, Mehrotra S, Caddell BA, Curry SR,Nolte FS, Babic N. Evaluation of Orthogonal Testing Algorithm for Detection of SARS-CoV-2 lgG Antibodies. Clin Chem. 2020;66(12)1531-7. DOI

52. Centers for Disease Control and Prevention. Interim Guidelines for COVID-19 Antibody Testing. Atlanta (GA); CDC; (modifié 2021-03). https://www.cdc.gov/coronavirus/2019-ncov/ lab/resources/antibody-tests-guidelines.html

53. Stadlbauer D, Amanat F, Chromikova V, Jiang K, Strohmeier S, Arunkumar GA, Tan J, Bhavsar D, Capuano C, Kirkpatrick E, Meade P, Brito RN, Teo C, McMahon M, Simon V, Krammer F. SARS-CoV-2 Seroconversion in Humans: A Detailed Protocol for a Serological Assay, Antigen Production, and Test Setup. Curr Protoc Microbiol 2020;57(1):e100. DOI PubMed

54. Coste AT, Jaton K, Papadimitriou-Olivgeris M, Greub G, Croxatto A. Comparison of SARS-CoV-2 serological tests with different antigen targets. J Clin Virol 2021;134:104690. DOI PubMed

55. DomBourian MG. Annen K, Huey L, Andersen G, Merkel PA, Jung S, Dominguez SR, Knight V. Analysis of COVID-19 convalescent plasma for SARS-CoV-2 lgG using two commercial immunoassays. J Immunol Methods 2020;486:112837. DOI

56. Turbett SE, Anahtar M, Dighe AS, Garcia Beltran W, Miller T, Scott H, Durbin SM, Bharadwaj M, Thomas J, Gogakos TS, Astudillo M, Lennerz J, Rosenberg ES, Branda JA. Evaluation of Three Commercial SARS-CoV-2 Serologic Assays and Their Performance in Two-Test Algorithms. J Clin Microbiol 2020;59(1):e01892-20. DOI PubMed

57. Hoste AC, Venteo A, Fresco-Taboada A, Tapia I, Monedero A, López L, Jebbink MF, Pérez-Ramírez E, Jimenez-Clavero MA, Almonacid M, Muñoz P, Guinea J, Vela C, van der Hoek L, Rueda P, Sastre P. Two serological approaches for detection of antibodies to SARS-CoV-2 in different scenarios: a screening tool and a point-of-care test. Diagn Microbiol Infect Dis 2020;98(4):115167. DOI PubMed

58. Pallett SJ, Jones R, Pallett MA, Rayment M, Mughal N, Davies GW, Moore LS. Characterising differential antibody response is integral to future SARS-CoV-2 serostudies. J Infect 2020;81(6):e28-30. DOI PubMed

59. Perkmann T, Perkmann-Nagele N, Oszvar-Kozma M, Koller T, Breyer M-K, Breyer-Kohansal R, Burghuber OC, Harti S, Aletaha D, Sieghart D, Quehenberger P, Marculescu R, Mucher P, Radakovics A, Strassl R, Leitner G, Wagner OF, Binder CJ, Haslacher $\mathrm{H}$. Increasing both specificity and sensitivity of SARS-CoV-2 antibody tests by using an adaptive orthogonal testing approach. medRxiv. 2020.11.05.20226449. (Publié en ligne avant impression). DOI

60. Ng DL, Goldg of GM, Shy BR, Levine AG, Balcerek J, Bapat SP, Prostko J, Rodgers M, Coller K, Pearce S, Franz S, Du L, Stone M, Pillai SK, Sotomayor-Gonzalez A, Servellita V, Martin CS, Granados A, Glasner DR, Han LM, Truong K, Akagi N, Nguyen DN, Neumann NM, Qazi D, Hsu E, Gu W, Santos YA, Custer B, Green V, Williamson P, Hills NK, Lu CM, Whitman JD, Stramer SL, Wang C, Reyes K, Hakim JM, Sujishi K, Alazzeh F, Pham L, Thornborrow E, Oon CY, Miller S, Kurtz T, Simmons G, Hackett J Jr, Busch MP, Chiu CY. SARS-CoV-2 seroprevalence and neutralizing activity in donor and patient blood. Nat Commun 2020;11(1):4698. DOI PubMed 
61. Kaufer AM, Theis T, Lau KA, Gray JL, Rawlinson WD. Laboratory biosafety measures involving SARS-CoV-2 and the classification as a Risk Group 3 biological agent. Pathology 2020;52(7):790-5. DOI PubMed

62. Lee WT, Girardin RC, Dupuis AP, Kulas KE, Payne AF, Wong SJ, Arinsburg S, Nguyen FT, Mendu DR, Firpo-Betancourt A, Jhang J, Wajnberg A, Krammer F, Cordon-Cardo C, Amler S, Montecalvo M, Hutton B, Taylor J, McDonough KA. Neutralizing Antibody Responses in COVID-19 Convalescent Sera. J Infect Dis 2021;223(1):47-55. DOI PubMed

63. Mendoza EJ, Manguiat K, Wood H, Drebot M. Two Detailed Plaque Assay Protocols for the Quantification of Infectious SARS-CoV-2. Curr Protoc Microbiol. 2020;57(1):ecpmc105. DOI

64. Crawford KH, Eguia R, Dingens AS, Loes AN, Malone KD, Wolf CR, Chu HY, Tortorici MA, Veesler D, Murphy M, Pettie D, King NP, Balazs AB, Bloom JD. Protocol and Reagents for Pseudotyping Lentiviral Particles with SARS-CoV-2 Spike Protein for Neutralization Assays. Viruses 2020;12(5):513. DOI PubMed

65. Tan CW, Chia WN, Qin X, Liu P, Chen MI, Tiu C, Hu Z, Chen VC, Young BE, Sia WR, Tan YJ, Foo R, Yi Y, Lye DC, Anderson DE, Wang LF. A SARS-CoV-2 surrogate virus neutralization test based on antibody-mediated blockage of ACE2-spike protein-protein interaction. Nat Biotechnol 2020;38(9):1073-8. DOI PubMed

66. Muruato AE, Fontes-Garfias CR, Ren P, Garcia-Blanco MA, Menachery VD, Xie X, Shi PY. A high-throughput neutralizing antibody assay for COVID-19 diagnosis and vaccine evaluation. Nat Commun 2020;11(1):4059. DOI PubMed

67. Abe KT, Li Z, Samson R, Samavarchi-Tehrani P, Valcourt EJ, Wood H, Budylowski P, Dupuis AP $2^{\text {nd }}$, Girardin RC, Rathod B, Wang JH, Barrios-Rodiles M, Colwill K, McGeer AJ, Mubareka S, Gommerman JL, Durocher Y, Ostrowski M, McDonough KA, Drebot MA, Drews SJ, Rini JM, Gingras AC. A simple protein-based surrogate neutralization assay for SARS-CoV-2. JCl Insight 2020;5(19):e142362. DOI PubMed

68. Meyer B, Reimerink J, Torriani G, Brouwer F, Godeke GJ, Yerly S, Hoogerwerf M, Vuilleumier N, Kaiser L, Eckerle I, Reusken C. Validation and clinical evaluation of a SARS-CoV-2 surrogate virus neutralisation test (sVNT). Emerg Microbes Infect 2020;9(1):2394-403. DOI PubMed

69. Valcourt EJ, Manguiat K, Robinson A, Chen JC, Dimitrova K, Philipson C, Lamoureux L, McLachlan E, Schiffman Z, Drebot MA, Wood $\mathrm{H}$. Evaluation of a commercially-available surrogate virus neutralization test for severe acute respiratory syndrome coronavirus-2 (SARS-CoV-2). Diagn Microbiol Infect Dis 2021;99(4):115294. DOI PubMed

70. Taylor SC, Hurst B, Charlton CL, Bailey A, Kanji JN, McCarthy MK, Morrison TE, Huey L, Annen K, DomBourian MG, Knight V. A New SARS CoV-2 Dual Purpose Serology Test: Highly Accurate Infection Tracing and Neutralizing Antibody Response Detection. J Clin Microbiol. 2021;JCM.02438-20. DOI

71. Riepler L, Rössler A, Falch A, Volland A, Borena W, von Laer D, Kimpel J. Comparison of Four SARS-CoV-2 Neutralization Assays. Vaccines (Basel) 2020;9(1):13. DOI PubMed
72. Perera RA, Mok CK, Tsang OT, Lv H, Ko RL, Wu NC, Yuan M, Leung WS, Chan JM, Chik TS, Choi CY, Leung K, Chan KH, Chan KC, Li KC, Wu JT, Wilson IA, Monto AS, Poon LL, Peiris M. Serological assays for severe acute respiratory syndrome coronavirus 2 (SARS-CoV-2), March 2020. Euro Surveill 2020;25(16):2000421. DOI PubMed

73. Bonelli F, Sarasini A, Zierold C, Calleri M, Bonetti A, Vismara C, Blocki FA, Pallavicini L, Chinali A, Campisi D, Percivalle E, DiNapoli AP, Perno CF, Baldanti F. Clinical and Analytical Performance of an Automated Serological Test That Identifies S1/S2-Neutralizing IgG in COVID-19 Patients Semiquantitatively. J Clin Microbiol 2020;58(9):e01224-20. DOI PubMed

74. Valdivia A, Torres I, Latorre V, Francés-Gómez C, Albert E, Gozalbo-Rovira R, Alcaraz MJ, Buesa J, Rodríguez-Díaz J, Geller R, Navarro D. Inference of SARS-CoV-2 spike-binding neutralizing antibody titers in sera from hospitalized COVID-19 patients by using commercial enzyme and chemiluminescent immunoassays. Eur J Clin Microbiol Infect Dis 2021;40(3):485-94. DOI PubMed

75. Patel EU, Bloch EM, Clarke W, Hsieh YH, Boon D, Eby $Y$, Fernandez RE, Baker OR, Keruly M, Kirby CS, Klock E, Littlefield K, Miller J, Schmidt HA, Sullivan P, Piwowar-Manning E, Shrestha R, Redd AD, Rothman RE, Sullivan D, Shoham S, Casadevall A, Quinn TC, Pekosz A, Tobian AA, Laeyendecker O. Comparative Performance of Five Commercially Available Serologic Assays To Detect Antibodies to SARS-CoV-2 and Identify Individuals with High Neutralizing Titers. J Clin Microbiol 2021;59(2):e02257-20. DOI PubMed

76. L'Huillier AG, Meyer B, Andrey DO, Arm-Vernez I, Baggio S, Didierlaurent A, Eberhardt CS, Eckerle I, Grasset-Salomon C, Huttner A, Posfay-Barbe KM, Royo IS, Pralong JA, Vuilleumier N, Yerly S, Siegrist CA, Kaiser L. Geneva Centre for Emerging Viral Diseases. Antibody persistence in the first 6 months following SARS-CoV-2 infection among hospital workers: a prospective longitudinal study. Clin Microbiol Infect. 2021;S1198-743X(21)00031-8. DOI

77. Iyer AS, Jones FK, Nodoushani A, Kelly M, Becker M, Slater D, Mills R, Teng E, Kamruzzaman M, Garcia-Beltran WF, Astudillo M, Yang D, Miller TE, Oliver E, Fischinger S, Atyeo C, lafrate AJ, Calderwood SB, Lauer SA, Yu J, Li Z, Feldman J, Hauser BM, Caradonna TM, Branda JA, Turbett SE, LaRocque RC, Mellon G, Barouch DH, Schmidt AG, Azman AS, Alter G, Ryan ET, Harris JB, Charles RC. Persistence and decay of human antibody responses to the receptor binding domain of SARS-CoV-2 spike protein in COVID-19 patients. Sci Immunol 2020;5(52):eabe0367. DOI PubMed

78. Wendel S, Fontão-Wendel R, Fachini R, Candelaria G, Scuracchio $P$, Achkar R, Brito M, Reis LF, Camargo A, Amano M, Machado R, Araujo D, Soares C, Durigon E. A longitudinal study of convalescent plasma (CCP) donors and correlation of $A B O$ group, initial neutralizing antibodies $(n A b)$, and body mass index (BMI) with nAb and anti-nucleocapsid (NP) SARS-CoV-2 antibody kinetics: proposals for better quality of CCP collections. Transfusion 2021. (Publié en ligne avant impression). DOI PubMed

79. Comité consultatif national de l'immunisation (CCNI). Vaccin contre la varicelle: Guide canadien d'immunisation. Ottawa (ON) : CCNI; 2018. https://www.canada.ca/fr/ sante-publique/services/publications/vie-saine/guide-canadie n-immunisation-partie-4-agents-immunisation-active/page24-vaccin-contre-varicelle.html 
80. Fenwick $C$, Croxatto $A$, Coste AT, Pojer F, André $C$, Pellaton C, Farina A, Campos J, Hacker D, Lau K, Bosch BJ, Gonseth Nussle S, Bochud M, D'Acremont V, Trono D, Greub G, Pantaleo G. Changes in SARS-CoV-2 Spike versus Nucleoprotein Antibody Responses Impact the Estimates of Infections in Population-Based Seroprevalence Studies. J Virol 2021;95(3):e01828-20. DOl PubMed

81. Kupferschmidt K. New coronavirus variants could cause more reinfections, require updated vaccines. Science 2021. https://www.sciencemag.org/news/2021/01/ new-coronavirus-variants-could-cause-more-reinfections-req uire-updated-vaccines

82. European Centre for Disease Prevention and Control. Risk Assessment: Risk related to spread of new SARS-CoV-2 variants of concern in the EU/EEA. ECDC; 2020.

https://www.ecdc.europa.eu/en/publications-data/covid-19-riskassessment-spread-new-sars-cov-2-variants-eueea

83. World Health Organization. SARS-CoV-2 Variants. Geneva (Switzerland): WHO; 2020. https://www.who.int/csr/don/31december-2020-sars-cov2-variants/en/

84. Greaney AJ, Loes AN, Crawford KH, Starr TN, Malone KD, Chu HY, Bloom JD. Comprehensive mapping of mutations in the SARS-CoV-2 receptor-binding domain that affect recognition by polyclonal human plasma antibodies. Cell Host Microbe 2021;29(3):463-476.e6. DOI PubMed

85. Wibmer CK, Ayres F, Hermanus T, Madzivhandila M, Kgagudi $P$, Lambson BE, de Oliveira $T$, Vermeulen $M$, van der Berg K, Rossouw T, Boswell M, Ueckermann V, Meiring $S$, von Gottberg A, Cohen C, Morris L, Bhiman JN, Moore PL. SARS-CoV-2 501Y.V2 escapes neutralization by South African COVID-19 donor plasma. bioRxiv. 2021.01.18.427166. (Publié en ligne avant impression). DOI
86. Wang Z, Schmidt F, Weisblum Y, Muecksch F, Barnes CO, Finkin S, Schaefer-Babajew D, Cipolla M, Gaebler C, Lieberman JA, Oliveira TY, Yang Z, Abernathy ME, Huey-Tubman KE, Hurley A, Turroja M, West KA, Gordon K, Millard KG, Ramos V, Da Silva J, Xu J, Colbert RA, Patel R, Dizon J, Unson-O'Brien C, Shimeliovich I, Gazumyan A, Caskey M, Bjorkman PJ, Casellas R, Hatziioannou T, Bieniasz PD, Nussenzweig MC. mRNA vaccine-elicited antibodies to SARS-CoV-2 and circulating variants. Nature. 2021;592:616-22. (Publié en ligne avant impression). DOI

87. Naveca F, da Costa C, Nascimento V, Souza V, Corado A, Nascimento F, Costa A, Duarte D, Silva G, Mejia M, Pessoa K, Goncalves L, Brandao MJ, Jesus M, Pinto R, Silva M, Mattros T, Abdalla L, Santos JH, Costa-Filho R, Wallau GL, Siqueira MM, Delatorre E, Graf T, Bello G, Resende PC. SARS-CoV-2 reinfection by the new Variant of Concern (VOC) P.1 in Amazonas, Brazil. Virological. Jan 17, 2021. https://virological. org/t/sars-cov-2-reinfection-by-the-new-variant-of-concern-vocp-1-in-amazonas-brazil/596

88. Comité consultative national de l'immunization (CCNI). Recommandations sur I'utilisation des vaccins contre la COVID-19. Ottawa (ON) : CCNI; 2021. https://www.canada. $\mathrm{ca} / \mathrm{fr} /$ sante-publique/services/immunisation/comite-consultati f-national-immunisation-ccni/recommandations-utilisatio n-vaccins-covid-19.html 